Nat. Hazards Earth Syst. Sci., 20, 1045-1048, 2020

https://doi.org/10.5194/nhess-20-1045-2020

(C) Author(s) 2020. This work is distributed under

the Creative Commons Attribution 4.0 License.

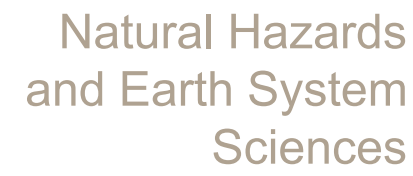

(c) (P)

\title{
Preface: Advances in flood risk assessment and management
}

\author{
Cristina Prieto ${ }^{1,2,3}$, Dhruvesh Patel ${ }^{4}$, and Dawei Han $^{3}$ \\ ${ }^{1}$ IHCantabria - Instituto de Hidráulica Ambiental de la Universidad de Cantabria, Santander, Spain \\ ${ }^{2}$ Department of Civil and Environmental Engineering, Imperial College London, London, UK \\ ${ }^{3}$ Department of Civil Engineering, Bristol University, Bristol, UK \\ ${ }^{4}$ Department of Civil Engineering, School of Technology, Pandit Deendayal Petroleum University, Gujarat, India
}

Correspondence: Cristina Prieto (prietoc@unican.es)

Received: 2 April 2020 - Published: 17 April 2020

\begin{abstract}
Floods are among Earth's most common and most destructive natural hazards, affecting human lives and properties directly and indirectly around the world. The frequency and magnitude of extreme flooding have been increasing in many parts of the world in recent decades (see, e.g. Berghuijs et al., 2017; Blöschl et al., 2019a; Marijnissen et al., 2019), hampering human well-being and economic growth in both developed and developing countries. Flood risk management carries out the flood risk assessment and uses appropriate resources (human, finance, science and technology, and nature) to control the flood risk (Han, 2011), which is an urgent challenge for the scientific and engineering communities to address.

In a similar way to "Twenty-three unsolved problems in hydrology" (Blöschl et al., 2019b), despite decades of research in this field, there are still many unsolved problems in floods as well. This special issue "Flood Risk Assessment and Management" is an outcome of the session "Flood Risk Assessment and Management" in the Naturals Hazards Division at the European Geosciences Union (EGU) General Assembly held in Vienna, Austria. The session series has been organized annually at EGU since 2018. This special issue presents a wide range of in-depth research studies based on flood modelling (including hydrological modelling and hydrodynamic modelling), hazard mapping, flood damage and risk assessment as well as studies that focus on flood relief prioritization, mitigation strategies and flood policies. Extraordinary floods and debris flows are also included due to dam and dike breaks and extreme storms over gullies in mountain areas. The nine articles in this special issue are broadly introduced in the following three categories.
\end{abstract}

\section{Flood and related hazards}

\subsection{Delimitation of flood areas based on a calibrated DEM and geoprocessing: case study on the Uruguay River, Itaqui, southern Brazil (Araújo et al., 2019)}

Hazard maps of river flooding are crucial information for planning and intervention in flood-prone areas. This is a process of determining inundation extent and depth by comparing historical and designed river water levels with ground surface elevation references. There are limited studies that involve mapping to assess potential flood damage in many developing countries, which is particularly so in Brazil. In the work of Araújo et al. (2019), flood areas in southern Brazil are delimitated based on a calibrated digital elevation model and geoprocessing techniques. The case study of the Uruguay River (Itaqui in the state of Rio Grande do Sul) is presented. Flood hazard areas are mapped using a free digital elevation model from the Shuttle Radar Topography Mission. It is calibrated with ground control points based on post-processed high-precision global navigation satellite system surveys. Flood episodes are modelled with a return period of 100 years derived from historic maximum annual river level records collected from the Itaqui station during the years 1942-2017. The digital flood map produced can be used as a database to assist governmental stakeholders in the implementation of flood risk management plans that are more adaptable to local restrictive environmental constraints. The study highlights that the adopted methodological approach is effective for mitigating flooding damage in coastal and riparian areas, and it is valuable in reducing strategic monitoring 
costs and the operational expenses of providing assistance to the population affected by severe flooding events and their consequences.

\subsection{Study on the combined threshold for gully-type debris flow early warning (Huang et al., 2019)}

In mountainous regions, gully-type debris flows tend to occur together with flash floods, as both are usually triggered by high-intensity and short-duration rainstorms. Therefore, it is important to consider such hazards when dealing with maintaining flood risk management. Early warning systems have been provided to reduce the risk by such hazards. However, traditional methods mainly focus on rainfall thresholds, with no consideration of the rise of loosely deposited material and unstable slopes, which are distributed along the catchments. Huang et al. (2019) present a study that uses a combined threshold for the early warning of gully-type debris flows. The proposed method uses both rainfall threshold and critical pore pressure determined by a hydro-mechanical stability model. The Wenjia gully in China is selected as its case study to explore a comprehensive method for gully-type debris flow early warning by real-time monitoring of rainfall and pore pressure in the material deposited along channels. The results show that the combined threshold is a reliable approach for the early warning of gully-type debris flow to serve the population in the mountainous areas.

\section{Flood damages}

\subsection{Towards risk-based flood management in highly productive paddy rice cultivation - concept development and application to the Mekong Delta (Triet et al., 2018)}

Flood risk assessment involves proper estimation of hazard and consequent damage. Compared with a large number of hazard studies, research on flood damage is rather limited, particularly in agricultural lands. Triet et al. (2018) present a large-scale flood risk assessment for the agricultural sector in the Vietnamese Mekong Delta. The authors focus on rice paddies, which are the predominant crop type in the delta. Its methodological novelty lies in the detailed consideration of the cropping calendar and plant phenomenology in combination with synthetic probabilistic flood hydrographs. The study evaluates two land-use scenarios, one with intensified rice cropping and the other one with reduced rice cropping. The risk indicators considered are the expected annual damage and the average crop risk. These indicators serve as the basis for the cost-benefit analysis of the two land-use development scenarios proposed in the Mekong Delta Plan. The results shows that the flood timing, the high tide and the cropping calendar are crucial factors in estimating agricultural crop damage. The risk indicators used in this study can serve as a basis on which to develop spatially explicit flood management and mitigation plans for the delta. Additionally, these maps may support the recently initiated agricultural insurance programme in Vietnam.

\subsection{Testing empirical and synthetic flood damage models: the case of Italy (Amadio et al., 2019)}

Flood risk management relies on economic assessments using flood loss models. Amadio et al. (2019) compare expertbased vs empirical uni- and multivariable damage models to estimate the economic costs of flood events to residential buildings. The project team collect a large empirical dataset related to three recent major flood events in northern Italy. This dataset includes the following information for each event: (1) hazard characterization derived from observational data and/or hydraulic modelling, (2) high-resolution exposure (location, size, typology, economic value, etc.), and (3) declared costs per damage category. The study employs supervised-learning algorithms for exploring the parameters of hazard, exposure and vulnerability and their influence on damage magnitude. They test linear, logarithmic and squareroot regression functions to select the best-suited univariable and bivariable models, and two supervised machine-learning algorithms (random forest and artificial neural networks), for training and testing the empirical multivariable models. These models provide a benchmark for testing the performance of four models in the literature, which are specifically developed for Italy. It is found that water depth is the most important predictor of flood damage, followed by secondary variables related to the hazard (flow velocity and duration) and exposure features (area, perimeter and replacement value of the building). Multivariable models are found to produce reliable damage estimates when extensive ancillary data for flood event characterization are available, while univariable models are adequate for scarce data environments. Finally, in Italy, the synthetic models are the best option for damage prediction purposes when extensive loss data are not available for deriving a location-specific flood damage model. They conclude that empirical damage data are the most important set of information for improving and validating damage models, so the authors recommend a shared effort towards an updated catalogue of floods that includes hazard, exposure and damage information at the micro-scale. To this end, the adoption of a standardized and detailed procedure for damage data collection is considered to be a mandatory step.

\subsection{Weight analysis of influencing factors of dam break risk consequences ( $\mathrm{Li}$ et al., 2018)}

Floods caused by dam break are a kind of low-probability and high-loss risk. There has been limited research in this area. The paper of Li et al. (2018) paper establishes a weight calculation model for dealing with the influencing factors of dam break risk consequences. Twenty factors have been taken into account, covering hazards, exposure and vulnera- 
bility to construct the evaluation index system on the dam break consequences. The authors use the statistical cloud model to improve the entropy method for analysing the weight of influencing factors. This provides a basis for research on the dam break risk evaluation and for the establishment and improvement of dam risk management theory. The results indicate that the five factors with the highest weight are exposed population, flood intensity, alert time, risk understanding and distance from the dam, which are consistent with the algebraic weight distribution. The proposed model has the advantage of extensive applicability, benefiting from the flexibility of index selection and the independence of expert scoring, providing a solid foundation for risk assessment and risk management theory.

\section{Mitigation}

\subsection{Towards multi-objective optimization of large-scale fluvial landscaping measures (Straatsma et al., 2019)}

Coastal deltas are particularly prone to flooding because of the coincidence of peak river discharges and storm surges, the backwater effect due to sea level rises, the urbanization combined with the associated land subsidence, etc. Adapting densely populated deltas to the combined impacts of climate change and socioeconomic developments presents a major challenge for sustainable development in the 21st century. A key issue for such environmental management is the number and diversity of the actors and sectors involved in the decision process because each has its own perceptions, interests and resources. Therefore, a multi-objective optimization of large-scale fluvial landscaping measures is required. Straatsma et al. (2019) have quantified the variable trade-offs of common measures to compensate for an increase in discharge and sea level rise. Their case study has looked at the largest delta distributary of the Rhine River, with 17 adaptation scenarios driven by (1) the choice of seven measures, (2) the areas owned by the two largest stakeholders vs all stakeholders, and (3) the ecological or hydraulic design principle. The measures are evaluated by their efficiency in flood hazard reduction, potential biodiversity, number of stakeholders as a proxy for governance complexity and measure implementation cost. It is found that only floodplain lowering over the whole study area can offset the altered hydrodynamic boundary conditions, and natural management of meadows, after roughness smoothing and floodplain lowering, represents the optimum combination between potential biodiversity and flood hazard lowering. With this set-up, the state of the art moves away from the traditional hydraulicsonly analysis towards multidisciplinary, multi-parametric, multi-objective optimizations for supporting the negotiations among stakeholders in the decision-making process.

\subsection{Re-evaluating safety risks of multifunctional dikes with a probabilistic risk framework (Marijnissen et al., 2019)}

Flood protection structures are often engineered with additional functions which are termed multifunctional flood defences (MFFDs). In the Netherlands, combining dikes with other functions is fairly common (e.g. roads on top, cables and/or pipelines running through them, or structures on them or that are part of a historic landscape). However, the tools to assess the safety of MFFDs are still limited. The means to determine the safety provided by multifunctional flood defences remain conservative approaches in dealing with individual functions. The study of Marijnissen et al. (2019) provides a new analysis on how a full probabilistic approach towards multifunctional flood defences can change the assessed safety compared with the conservative approach. It argues that application of a probabilistic approach towards multifunctional use of the flood defence will lead to a lower assessed risk of flooding compared with conservative assessments. It is found that monofunctional dikes with high reliability are more suitably combined with multifunctional uses detrimental to safety, whereas dikes with low reliability can benefit more from multifunctional uses that contribute to safety. Further research is required on the proper scenarios and their associated probabilities that can be used to improve future assessments of multifunctional dikes. In addition, with the large uncertainties under climate change, more research is needed to assess how multifunctional elements influence the safety of dikes over longer periods.

\subsection{Uncertainty quantification of flood mitigation predictions and implications for interventions (Berends et al., 2019)}

Reduction of water levels during river floods is key in mitigating damage and loss of life. Assessment of various mitigation options is based on computational modelling, whose uncertainty influences decision-making. Since model predictions are uncertain, they in turn affect accurate predictions of optional flood mitigation strategies. The paper of Berends et al. (2019) explores a new method for quantifying the uncertainties of flood mitigation options and their implications in designing effective interventions. The case study at the Dutch river Waal is based on 39 different sources of uncertainties and 12 intervention designs. Relative uncertainty (RU) is used to compare uncertainties between different interventions. It is defined as the ratio between the confidence interval and the expected effect. The study demonstrates that the uncertainty behaviour follows a traditional backwater curve with an approximately constant relative uncertainty value. It is found that the higher the flood level, the higher the uncertainty and vice versa. However, different interventions with the same expected effect do not necessarily have the same uncertainty. For example, in their case study the large-scale but 
relatively ineffective intervention of floodplain smoothing by removing vegetation has much higher uncertainty compared with the alternative options. The study emphases that for real-world problems, uncertainty quantification is necessary in effectively evaluating alternative flood intervention strategies.

\subsection{Climate risks, digital media and big data: following communication trails to investigate urban communities' resilience (Vicari et al., 2019)}

For urban resilience assessment on climate risks, "big" data exploration techniques can be exploited using digital media. The interaction between climate-related risks and the social perception of these risks can be monitored to derive the effect of these interactions on urban resilience. The case study of Vicari et al. (2019) in two French urban areas has extracted three corpora of Web communication data: press articles covering the October 2015 Alpes-Maritimes flood, press articles covering the June 2016 Seine River flood and tweets on the 2016 Seine River flood. Their analysis involves hundreds of key terms by looking at their incidence and measuring semantic proximity (conditional distance) between them. Via this analysis, the authors have found the topics and actors that characterize each press dataset, their most probable cooccurrences, and the clusters of topics and actors. Profiling of social media users allows identification of those who influence opinions on Twitter. The authors have also observed how some patterns change over time in different urban areas and digital media contexts. This research contributes to gaining a better understanding of public opinion as conveyed in the media, and the opinion influencers, which is advantageous for any urban resilience project.

Acknowledgements. We would like to express our sincere thanks to the entire team of the Editorial Office at Copernicus for their professional support. Moreover, we would like to acknowledge the efforts of all the contributing authors to this special issue and all the reviewers' support with their constructive advice. Their knowledge on different aspects of flood risk assessment and management has helped to further develop the individual ideas presented in the papers. We would especially like to thank Dr Heidi Kreibich for her advice and guidance in this editorial and its revision process.

\section{References}

Amadio, M., Scorzini, A. R., Carisi, F., Essenfelder, A. H., Domeneghetti, A., Mysiak, J., and Castellarin, A.: Testing empirical and synthetic flood damage models: the case of Italy, Nat. Hazards Earth Syst. Sci., 19, 661-678, https://doi.org/10.5194/nhess-19-661-2019, 2019.
Araújo, P. V. N., Amaro, V. E., Silva, R. M., and Lopes, A. B.: Delimitation of flood areas based on a calibrated a DEM and geoprocessing: case study on the Uruguay River, Itaqui, southern Brazil, Nat. Hazards Earth Syst. Sci., 19, 237-250, https://doi.org/10.5194/nhess-19-237-2019, 2019.

Blöschl, G., Hall, J., Viglione, A., Perdigão, R. A. P., Parajka, J., Merz, B., Lun, D., Arheimer, B., Aronica, G., Bilibashi, A., Boháč, M., Bonacci, O., Borga, M., Čanjevac, I., Castellarin, A., Chirico, G. B., Claps, P., Frolova, N., Ganora, D., Gorbachova, L., Gül, A., Hannaford, J., Harrigan, S., Kireeva, M., Kiss, A., Kjeldsen, T. R., Kohnová, S., Koskela, J. J., Ledvinka, O., Macdonald, N., Mavrova-Guirguinova, M., Mediero, L., Merz, R., Molnar, P., Montanari, A., Murphy, C., Osuch, M., Ovcharuk, V., Radevski, I., Salinas, J., Sauquet, E., Šraj, M., Szolgay, J., Volpi E., Wilson, D., Zaimi, K., and Živković, N.: Changing climate both increases and decreases European river floods, Nature 573, 108-111, https://doi.org/10.1038/s41586-019-1495-6, 2019a.

Berghuijs, W. R., Aalbers, E. E., Larsen, J. R., Trancoso, R., and Woods, R. A.: Recent changes in extreme floods across multiple continents, Environ. Res. Lett., 12, 114035, https://doi.org/10.1088/1748-9326/aa8847, 2017.

Berends, K. D., Straatsma, M. W., Warmink, J. J., and Hulscher, S. J. M. H.: Uncertainty quantification of flood mitigation predictions and implications for interventions, Nat. Hazards Earth Syst. Sci., 19, 1737-1753, https://doi.org/10.5194/nhess19-1737-2019, 2019.

Blöschl, G., Bierkens, M. F. P., Chambel, A., et al.: Twentythree unsolved problems in hydrology (UPH) - a community perspective, Hydrolog. Sci. J., 64, 1141-1158, https://doi.org/10.1080/02626667.2019.1620507, 2019b.

Han, D.: Flood Risk Assessment and Management, Bentham Science Publishers, UAE, 2011.

Huang, J., van Asch, T. W. J., Wang, C., and Li, Q.: Study on the combined threshold for gully-type debris flow early warning, Nat. Hazards Earth Syst. Sci., 19, 41-51, https://doi.org/10.5194/nhess-19-41-2019, 2019.

Li, Z., Li, W., and Ge, W.: Weight analysis of influencing factors of dam break risk consequences, Nat. Hazards Earth Syst. Sci., 18, 3355-3362, https://doi.org/10.5194/nhess-18-3355-2018, 2018.

Marijnissen, R., Kok, M., Kroeze, C., and van Loon-Steensma, J.: Re-evaluating safety risks of multifunctional dikes with a probabilistic risk framework, Nat. Hazards Earth Syst. Sci., 19, 737756, https://doi.org/10.5194/nhess-19-737-2019, 2019.

Straatsma, M. W., Fliervoet, J. M., Kabout, J. A. H., Baart, F., and Kleinhans, M. G.: Towards multi-objective optimization of large-scale fluvial landscaping measures, Nat. Hazards Earth Syst. Sci., 19, 1167-1187, https://doi.org/10.5194/nhess19-1167-2019, 2019.

Triet, N. V. K., Dung, N. V., Merz, B., and Apel, H.: Towards risk-based flood management in highly productive paddy rice cultivation - concept development and application to the Mekong Delta, Nat. Hazards Earth Syst. Sci., 18, 2859-2876, https://doi.org/10.5194/nhess-18-2859-2018, 2018.

Vicari, R., Tchiguirinskaia, I., Tisserand, B., and Schertzer, D.: Climate risks, digital media, and big data: following communication trails to investigate urban communities' resilience, Nat. Hazards Earth Syst. Sci., 19, 1485-1498, https://doi.org/10.5194/nhess19-1485-2019, 2019. 